\title{
Modernização e território: a influência das redes técnicas na produção do espaço social
}

Sara Luciana Alves de Aquino

\section{Q OpenEdition \\ 1 Journals}

\section{Electronic version}

URL: http://journals.openedition.org/espacoeconomia/2375

DOI: 10.4000/espacoeconomia.2375

ISSN: 2317-7837

\section{Publisher}

Núcleo de Pesquisa Espaço \& Economia

\section{Electronic reference}

Sara Luciana Alves de Aquino, «Modernização e território: a influência das redes técnicas na produção do espaço social », Espaço e Economia [Online], 9 | 2016, Online since 09 January 2017, connection on 24 September 2020. URL : http://journals.openedition.org/espacoeconomia/2375 ; DOI : https://doi.org/10.4000/espacoeconomia.2375

This text was automatically generated on 24 September 2020.

(C) NUPEE 


\section{Modernização e território: a influência das redes técnicas na produção do espaço social}

Sara Luciana Alves de Aquino

REFERENCES

CASTILHO, Denis. Modernização Territorial e Redes Técnicas em Goiás. Goiânia : Editora UFG, 2016, 228 páginas. 


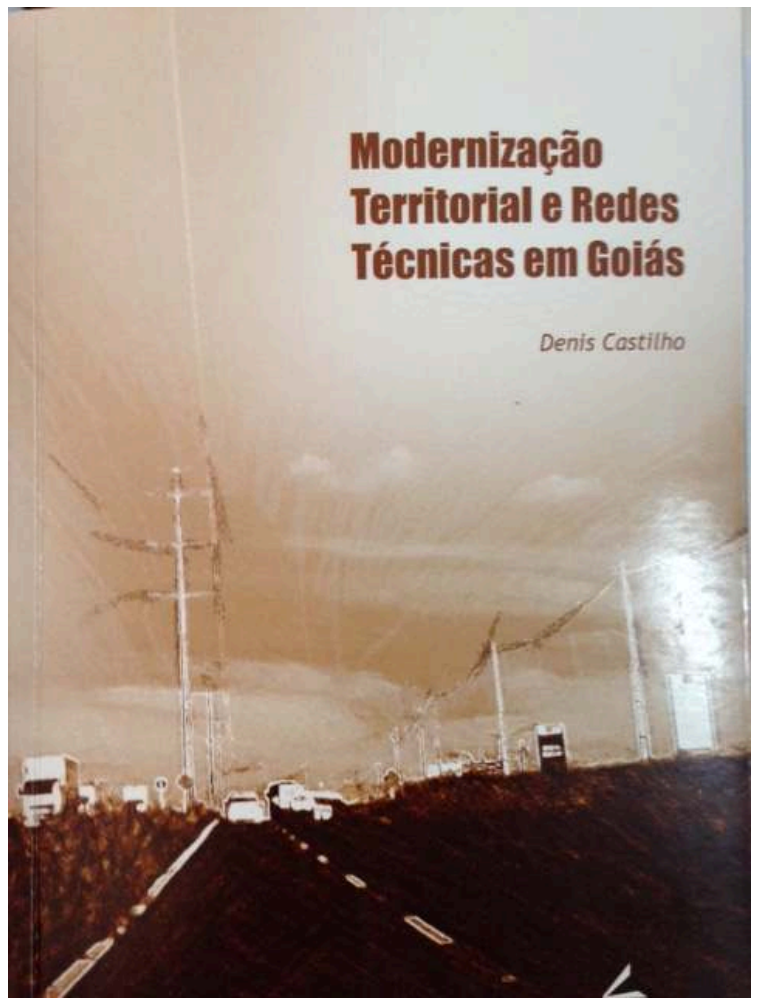

Foto da capa

1 “Modernização Territorial e Redes Técnicas em Goiás" (UFG, 2016, 228 páginas), fruto da tese de doutorado em Geografia, do geógrafo Denis Castilho, traz uma importante reflexão sobre modernização territorial como elemento estratégico de expansão do capitalismo. O autor utiliza esse conceito como matriz teórica a fim de entender a dimensão territorial da modernização no estado de Goiás, dada a partir das redes técnicas de transportes (ferroviária e rodoviária) e de energia elétrica. Nesta leitura, serão destacados alguns pontos do livro que, a nosso ver, levam o leitor a refletir sobre a outra face da modernização e das redes técnicas, visto que estas redes, quando entranhadas no cotidiano das pessoas, acabam por ser naturalizadas e pouco questionadas. Como revela o autor, para além do próprio discurso que associa a modernização a desenvolvimento e homogeneidade, o conceito mascara a possibilidade de que as sociedades, no curso de processos de modernização, tornem-se ainda mais desiguais sociais e economicamente. As ideias trazidas pelo autor não somente permitem a compreensão da expansão territorial em Goiás, mas se constituem elas próprias em uma potente formulação teórica útil para a compreensão da constituição de outras regiões do Brasil.

2 Castilho inicia seu trabalho destacando que seus objetivos se relacionam a correlacionar os sentidos possíveis do conceito de modernização e a resultante territorial desse processo. Portanto, a modernização como processo territorial se constitui numa matriz teórica a ser trabalhada no livro, considerada pelo autor como "resultado do modo como as forças hegemônicas capitalistas se expandem pelos lugares" (p. 20).

$\mathrm{O}$ autor procura distinguir os termos modernidade e modernização, identificando o primeiro como a instituição de um novo contexto histórico, delineado a partir das 
ideais iluministas e das revoluções inglesa e francesa, em que se instauram novas relações produtivas, e como um processo que influenciou a organização do espaço mundial e interligou os lugares. A modernização, disseminada com as mudanças do padrão produtivo, contudo, não segue um padrão universal, logo, é dada ao longo do tempo de diferentes formas em diferentes lugares, e num mesmo lugar a modernização atende de forma diferente a públicos diferentes, ou seja, a modernização está em constante adaptação no tempo e no espaço. Diante disso, o autor entende que não existe uma única modernização, mas há modernizações que correspondem a múltiplas escalas. Assim, o processo de modernização que ocorreu no Brasil deve ser analisado de forma particular, pois não segue o mesmo ritmo do processo de modernização europeu. E algo ainda bem relevante é como essa modernização brasileira, tão desigual, está diretamente ligada ao poder político controlador do território, poder este que favorece a manutenção da hegemonia da classe dominante. Por isso, existe a necessidade de controlar as redes técnicas, pois estas são um dos elementos por onde se dá o processo de modernização territorial. Compara-se aqui a rede com um fio condutor controlado pelo Estado, que ao interligar os lugares transporta e deixa ao mesmo tempo por onde passa: modernidade, inovação, conforto, exclusão, desigualdade social.

Não é por acaso que o livro, logo em sua introdução, manifesta que "o modo como essa modernização é pensada, produzida e controlada determina o seu sentido político e a caracteriza, antes de tudo, como desigual" (p. 15). Pode-se entender que o problema em si não é a modernização materializada nas redes técnicas, mas a maneira como elas (as redes) são controladas, para que servem e a quem servem, elementos importantes analisados no livro.

5 Entender a modernização (ou as modernizações) é não só o primeiro passo para desvendar a transformação territorial em função desse fenômeno, mas também é o caminho para apurar as consequências dessa modernização. $O$ autor destaca que a modernização, ao chegar nos lugares, levanta a bandeira da chegada de desenvolvimento, ocultando porém que, na prática, não passa de um crescimento econômico que não foi feito para atender as camadas populares, e que, pelo contrário, intensifica ainda mais o abismo da desigualdade social.

Em Goiás não é diferente. 0 estudo das redes mostra que, ao interligarem o estado principalmente à região sudeste - lugar de circulação intensa do capital -, a organização desse território foi atrelada aos propósitos da produção agrícola, agropecuária e mineral, ou seja, o objetivo não é servir a população, promover o desenvolvimento social, mas atender aos grandes grupos empresarias apoiados pelo poder político. Por isso, a importância desta leitura, pois de maneira clara e bem articulada Castilho apresenta e analisa o paradoxo intrínseco do fenômeno da modernização no território.

7 Em sua argumentação, Castilho, baseado nos trabalhos de Giddens (1991), entre outros autores relevantes, aponta o poder que a modernização tem de dirigir e "padronizar" (ao mesmo tempo que distinguir) o modo de vida das diferentes sociedades. Antes da modernidade, as relações sociais de cada sociedade se baseavam em lógicas específicas relativas às particularidades dos diferentes tempos e espaços. Porém, os processos que envolvem o desenvolvimento da modernidade padronizam o tempo e quebram não só a individualidade do tempo de cada espaço, mais também da singularidade das relações sociais. O espaço, por sua vez, visto como sinônimo de distância por alguns autores, ganha novo significado a partir da modernização, que por associar-se à velocidade, traz 
a ideia de redução do espaço em função da aceleração do tempo. Esta última ideia é criticada por Castilho, pois remete à compreensão de separação entre tempo e espaço, quando na verdade, segundo Harvey (1993), a agilidade na vinculação das informações na atualidade, resultado dos processos de modernização, acaba por comprimir a relação espaço-temporal. $O$ autor tem a preocupação, neste caso, de trazer o debate sobre o espaço e a modernização territorial relacionando de maneira engenhosa esses conceitos, considerando que, de acordo com Lefebvre (2000), sendo o espaço a resultante das relações sociais de produção, logo o processo de modernização necessita interligar os lugares para ampliar o modo de produção capitalista no território.

8 Com a leitura do livro, destaca-se a percepção de que a modernização é realizada para atender aos interesses de diferentes frações da classe dominante, sendo, portanto, uma modernização excludente, cujos meios e aspectos mais diretamente relacionados à exclusão são pouco estudados. Quando se fala de modernização e de sua materialização através das redes técnicas no Brasil e em Goiás, é comum o foco na falseadora sensação de desenvolvimento do país, porém pouco se debate ou se menciona na história, por exemplo, os trabalhadores que foram submetidos a condições precárias de trabalho nos processos de construção das linhas ferroviárias e os desdobramentos de alguns conflitos sociais como forma de resistência e protesto em relação a essas condições de trabalho.

Em sentido diverso, ao trazer o contexto dos processos de construção das estradas de ferro em Goiás, Castilho não omite as tensões vinculadas à modernização que foram negligenciadas na construção da história das redes técnicas. Quando analisa os documentos que serviram de base para o desenvolvimento de sua tese e não encontra registros dos conflitos dos trabalhadores que em diferentes esferas reivindicavam melhores condições de trabalho, o autor identifica uma "produção seletiva da história", a qual correspondem ocultações e dissimulações só reveladas por outras fontes de pesquisa, como as entrevistas feitas em pesquisa de campo, no caso da investigação desenvolvida por Castilho.

10 Após refletir sobre essa leitura, é improvável perceber as redes técnicas somente como meros meios tecnológicos de integração dos lugares, das pessoas e da economia, pois Castilho revela que suas funções vão além. Em essência, devemos ter em conta que as redes são instrumentos que abrem rotas para expandir o capitalismo e garantir ao mesmo tempo a manutenção da hegemonia de quem domina o Estado. Nessa perspectiva, o autor se reporta às questões territoriais inscritas nas concepções de Marx e Engels (1998), que enfatizam que “...a burguesia não pode deixar de expandir sem revolucionar, constantemente os instrumentos de produção e, desse modo, as relações de produção e, com elas todas as relações da sociedade" (p. 36). Por isso, o autor analisa os sentidos da modernização pela via tanto do meio técnico-produtivo quanto da dimensão política e territorial.

11 E o que seria viver sem as redes técnicas nos dias de hoje? Eis uma pergunta que parece uma provocação diante das formulações teóricas de Castilho. Pensar o porquê de as redes serem tão necessárias ao mundo contemporâneo e ao mesmo tempo serem demonizadas também faz parte da abordagem da obra e não é algo de difícil compreensão. É uma relação de sedução e dependência. Quanto mais uma sociedade se apropria dos meios tecnológicos, mais dependente desses meios essa sociedade e sua geração se tornam. Como assevera Dias (2003), um dos autores referidos por Castilho, pode-se resumir que as redes solidarizam, conectam e excluem. O subdesenvolvimento, 
a desigualdade espacial, a exclusão social são fenômenos que deveriam ser vistos claramente como consequência de uma sociedade vivendo no contexto da modernidade que se sustenta pelo modo capitalista de produção, não como fenômenos de uma sociedade "atrasada". Pode-se assim retomar a ideia de que as sociedades pré-modernas viviam dentro de lógicas próprias, de acordo com seu tempo. Hoje, com a disseminação e naturalização das redes, é difícil, quase impossível, enxergar a sociedade vivendo fora dos padrões tecnológicos do pós-modernismo. Portanto, as redes podem sim trazer conforto, agilidade e rapidez, mas para a população brasileira esses elementos são apenas migalhas de um plano que envolve o motivo do desenvolvimento tecnológico nacional.

12 Ao investigar as redes técnicas no Brasil, Castilho desenvolve seu trabalho a partir dos registros históricos das implantações das redes ferroviárias, pontuando primeiro o contexto nacional, com a implantação da primeira linha férrea do Brasil, em 1850, no estado do Rio de Janeiro, e depois identificando a implantação de outras linhas pelo território nacional. Em Goiás, a construção do primeiro trilho começa no início do século XX. Até então as malhas ferroviárias não estabeleciam uma unificação do mercado nacional, mais criaram fortes vínculos econômicos entre estados, como São Paulo e Goiás, por exemplo. Abordar o desenvolvimento da rede ferroviária no Brasil, porém, a pesquisa não se resume ao conteúdo escrito de relatos do contexto histórico, mais inclui também mapas que mostram como essa rede se expandiu ao longo do tempo no país, sobretudo na região sudeste, chegando ao estado de Goiás. A movimentação da rede ferroviária aconteceu inicialmente no sentido leste-oeste, visto que o objetivo era escoar o que se produzia no interior para os portos litorâneos. Apesar de esses novos acessos representarem interligação entre os lugares, contribuindo para a formação de novos fluxos populacionais, vê-se que essa modernização territorial é pensada em função da expansão do modo capitalista de produção e não para melhores condições de vida e de trabalho da população.

13 É importante observar que o livro não trata os processos analisados apenas como um marco histórico do processo de modernização do Brasil ou do estado goiano. A questão central são as novas características do território em função dessas transformações e as formas como as redes passaram a articular a organização territorial e as relações sociais. Um aspecto a se destacar, nesse caso, são as novas relações de trabalho: com a grande demanda para a instalação das vias ferroviárias, muitos trabalhadores de diferentes graus de qualificação foram direcionados para os locais de construção, produzindo-se uma nova experiência de trabalho, visto que nesse período estava sendo experimentada a inserção do trabalho assalariado em um contexto no qual ainda estava presente o trabalho escravo. É importante observar também o processo de ordenamento territorial do estado de Goiás, que passou a ser definido em torno das redes ferroviárias e dos fluxos por elas dinamizados, sempre a serviço do fortalecimento da hegemonia política da classe dominante.

14 Com um custo de construção e manutenção menor que as ferrovias, as redes rodoviárias passam a ganhar espaço e interligar no país, principalmente no sentido norte-sul. Em Goiás, inicialmente, as rodovias funcionavam em escala local, ligando cidades para complementar o funcionamento das ferrovias. Com o aumento da produtividade, esse meio de transporte foi ganhado escala nacional.

15 Por último e não menos importante, a rede de energia elétrica também tem um papel fundamental na formação e funcionamento do território. Com uma excelente coleção 
de dados históricos relativos à produção e ao consumo de energia, Castilho frisa como a distribuição desta está atrelada às dinâmicas econômicas que se arquitetam no território. A maneira como as redes de transmissão são organizadas em Goiás mostra que sua principal funcionalidade é atender os grupos hegemônicos que dominam o território.

16 Ao término do livro, Castilho traz uma reflexão indispensável à sua obra. Ao analisar a dimensão política do processo de modernização territorial brasileiro, sobretudo no território goiano, o autor ilustra como as redes técnicas de energia e transporte causam segregação, desigualdades e a formação dos espaços privilegiados. A diferenciação espacial pode ser, aparentemente, tomada como algo lógico, tendo em vista as diferentes atividades que contribuem na produção do espaço social. Contudo, a maneira como as redes técnicas induzem transformações na infraestrutura no território torna o espaço social desigual. Isso porque, retomando o que foi dito anteriormente, as redes são elementos de renovação e manutenção da hegemonia dos grupos dominantes. Assim, a evolução dessas redes no território forma os espaços privilegiados.

Enfim, a análise do livro traz uma contribuição fundamental para entender como a produção das redes técnicas está estritamente relacionada à expansão e evolução do capitalismo no território nacional e como essa transformação do espaço social, em função da modernização territorial, promove a desigualdade, que por sua vez é geradora de conflitos. Sobretudo, a leitura desde livro leva a refletir como o desejo pelo progresso e, mais do que isso, sua utilização como negócio, pode ser devastador. o livro é construído com uma escrita de fácil entendimento, de estrutura bem planejada entre os temas e subtemas, e apresenta uma excelente e plausível referência bibliográfica.

\section{AUTHOR}

\section{SARA LUCIANA ALVES DE AQUINO}

Formanda em Geografia pela Universidade do Estado do Rio de Janeiro, bolsista de Iniciação Científica / UERJ 